\title{
Analisis Kebijakan Pengelolaan dan Budidaya Ekosistem Gambut di Indonesia - Penerapan Pendekatan Advocacy Coalition Framework
}

\author{
Bergas Chahyo Baskoro $^{1}$, Cecep Kusmana ${ }^{2}$, Hariadi Kartodihardjo ${ }^{3}$ \\ Institut Pertanian Bogor, 16680. \\ [ $\underline{{ }^{1} \text { bergas.289@gmail.com }},{ }^{2}$ ckmangrove@gmail.com,$\underline{3 \text { hakabgr@gmail.com }]}$
}

\author{
Diterima: 30 October 2018 \\ Direview: 07 December 2018 \\ Diterbitkan : 31 December 2018 \\ Hak Cipta @ 2018 oleh Penulis (dkk) dan Jurnal \\ Sosial Humaniora (JSH) \\ *This work is licensed under the Creative \\ Commons Attribution International License (CC \\ BY 4.0). \\ http://creativecommons.org/licenses/by/4.0/
}

\begin{abstract}
Subject Area : Social and Politics (Sosial dan Politik)
\section{Abstract}

Indonesia has become the fourth largest owner of peat reserves in the world after Canada, Russia and the United States. Peatlands play a major role as carbon sinks and maintain a hydrological system. The destructive and oxidized characteristics of peat make the International and Indonesian Governments pay high attention to the management and protection of peat ecosystems. Through the Advocacy Coalition Framework (ACF) approach, this study found that there are a variety of actors and stakeholders who influence the dynamics of peat management and cultivation policy formulation in Indonesia. The actors and stakeholders formed a coalition by carrying out the logic of their respective belief systems, namely: Coalition A which has a belief system that peat land is a potential resource developed for cultivation and Coalition $B$ which has a belief system that views peat ecosystems as vulnerable ecosystems that must be protected and rehabilitated. The results of this study are expected to be able to provide recommendations needed in realizing sustainable management of peat ecosystems.
\end{abstract}

Keywords: peat ecosystem, peat land, cultivation, policy, advocacy coalition framework

\section{Pendahuluan}

Luas cadangan gambut Indonesia menempati posisi keempat terbesar di dunia setelah Kanada, Rusia, dan Amerika Serikat (Masganti 2017). Gambut memiliki sifat mudah rusak dan karakteristik yang berbeda dengan tanah mineral, sehingga pemanfaatannya harus sesuai dengan daya dukung yang dimiliki (Sabiham dan Sukarman 2012).

Kebijakan yang terkait dengan pengaturan pemanfaatan dan budidaya di lahan gambut oleh Pemerintah Indonesia telah dibuat sejak lebih dari 50 tahun silam dengan diskursus awal untuk memenuhi kebutuhan pangan nasional. Semenjak berakhirnya era orde baru, diskursus kebijakan mulai bergeser kepada paradigma pengelolaan dan perlindungan ekosistem gambut yang dipengaruhi oleh maraknya isu kebakaran lahan dan hutan, kerusakan sumberdaya alam, dan perubahan iklim, serta adanya perubahan koalisi pemerintah dengan organisasi masyarakat sipil (NGO/LSM) karena semakin menguatnya gerakan lingkungan hidup global dan terbukanya struktur kesempatan politik (Situmorang 2013; Ardhian et al. 2016). 
Dalam konteks pengelolaan dan budidaya, perubahan kebijakan yang ada berimplikasi pada keberlanjutan usaha budidaya yang dilakukan, baik oleh perusahaan maupun rakyat dengan skala yang beragam, serta mempengaruhi kinerja pengelolaan gambut yang berkelanjutan. Hal ini nampak pada implementasi Peraturan Pemerintah No. 71/2014 jo. Peraturan Pemerintah No. 57/2016 tentang Perlindungan dan Pengelolaan Ekosistem Gambut diharapkan mampu memberikan rekomendasi yang diperlukan dalam mewujudkan pengelolaan ekosistem gambut yang lestari.

\section{Metode Penelitian}

Penelitian ini dilakukan selama periode Maret - Oktober 2018 dengan lokasi di Jakarta, Bogor dan Kalimantan Barat, serta lokasi lain yang diperlukan. Pengumpulan data yang dilakukan meliputi data

\section{Gambar 1. Cakupan Pendekatan Advcacy Coalition Framework dalam Analisis Kebijakan}

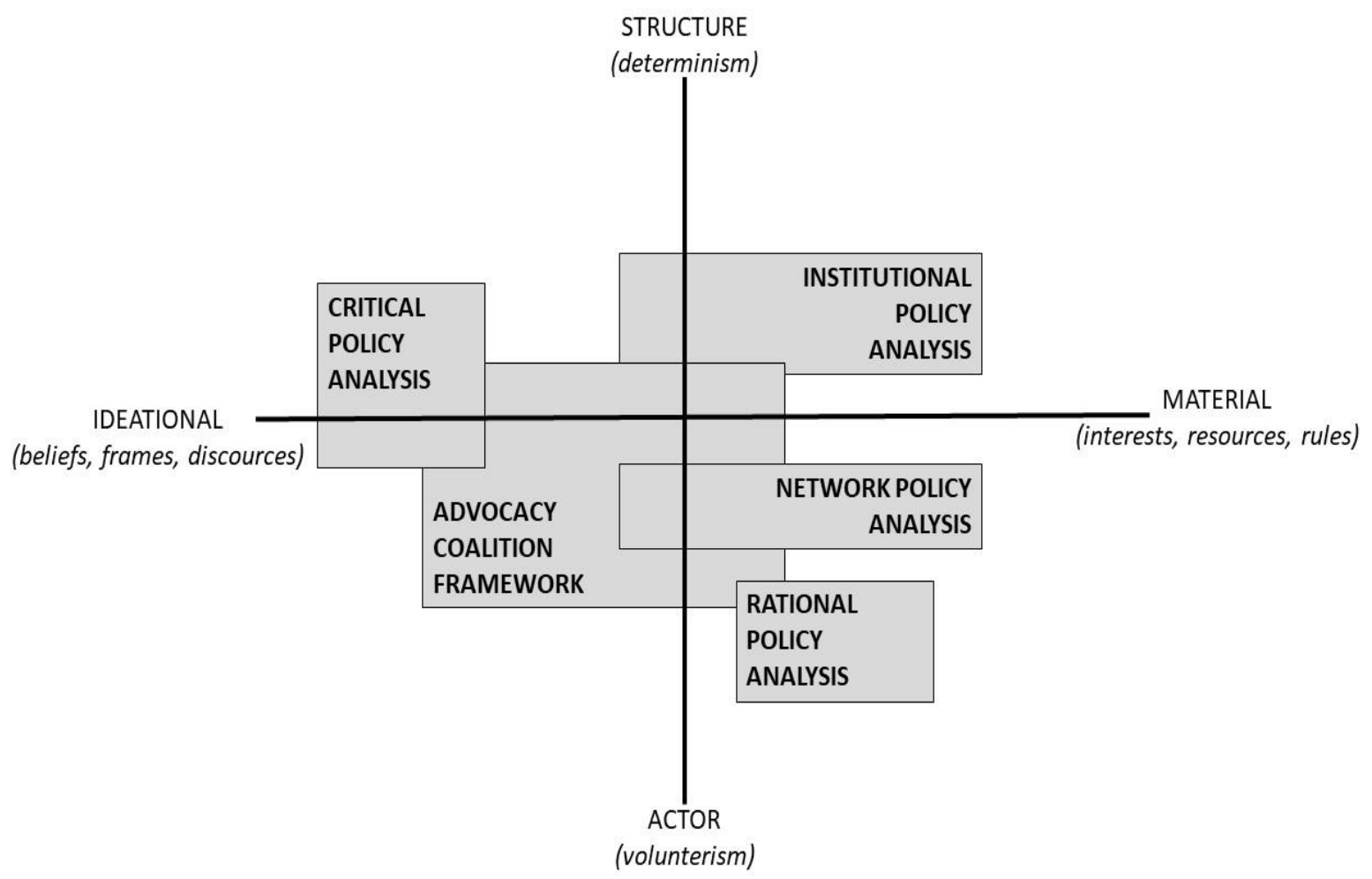

(Sumber: Arts 2012)

yang menuai pro dan kontra dari berbagai kalangan, termasuk akademisi, pengusaha, dan organisasi masyarakat sipil.

Penelitian ini dilakukan dengan tujuan untuk: (1) Menjelaskan dinamika kebijakan pengelolaan dan budidaya gambut di Indonesia; dan (2) Menentukan koalisi dalam arah kebijakan pengelolaan dan budidaya gambut yang terjadi dengan menggunakan kerangka pendekatan ACF. Hasil penelitian ini primer dan sekunder. Data primer merupakan dokumen produk aturan dan kebijakan, serta hasil wawancara secara terstruktur kepada masing-masing stakeholder. Sementara itu, data sekunder bersumber dari publikasi media massa, laporan penelitian, laporan kegiatan, dan dokumen lainnya yang digunakan untuk memperkuat hasil analisa dalam penelitian. 
Dalam rangka menjawab rumusan masalah penelitian yang pertama, digunakan strategi analisa diskursus terhadap dokumen kebijakan, laporan penelitian, laporan program kegiatan, dan sumber lain yang mendukung. Kerangka pendekatan ACF dipakai dalam menjawab rumusan masalah penelitian kedua dengan didukung oleh hasil analisa diskursus terhadap dokumen kebijakan, analisis wacana terhadap publikasi media massa dan hasil wawancara terhadap para pihak (stake holders) yang dipilih secara purposive.

Analisa kebijakan dengan menggunakan pendekatan Advocacy Coalition Framework (ACF) mengacu pada aktor, jaringan, dan situasi politik yang memberikan pengaruh pada kebijakan tersebut (Arshanti et al. 2017). Pada penelitian ini, dipilih kerangka pendekatan ACF karena apabila dibandingkan dengan pendekatan lainnya (Gambar 1), ACF mampu melihat perubahan aktor dan jaringan koalisi pembentuknya dalam sub-sistem kebijakan, termasuk perubahan sistem keyakinan yang dimiliki melalui adanya proses pembelajaran secara terusmenerus (Henry et al. 2014).

Berdasarkan hasil penelitian Sotirov dan Memmler (2012) yang telah menelaah 41 bentuk penggunaan kerangka pendekatan ACF pada berbagai hasil studi kebijakan sumberdaya alam, menunjukkan bahwa ACF mampu menjelaskan dengan baik perdebatan kebijakan yang berlangsung lama dengan melibatkan pertentangan nilai dan persaingan pengetahuan pada beragam domain geografis dan sistem politik di berbagai negara.

\section{Hasil Penelitian dan Pembahasan}

Dinamika Kebijakan Pengelolaan dan Budidaya Gambut
Pendekatan kerangka ACF mensyaratkan premis perubahan teks kebijakan yang terjadi selama kurun waktu lebih dari 10 tahun. Oleh karenanya, analisa dilakukan terhadap produk kebijakan terkait pengelolaan dan budidaya gambut selama kurun waktu tahun 1990 - 2017 yang dibagi menjadi tiga periode, yakni sebelum tahun 2007, tahun 2007 2014, dan 2014 - 2017. Pembagian periode ini terutama didasarkan pada respon pemerintah melalui produk kebijakan yang dikeluarkan terhadap fenomena sosial-politik di Indonesia. Diskursus kebijakan pengelolaan dan budidaya gambut di Indonesia dapat dilihat pada Tabel 1.

\section{Periode Sebelum Tahun 2007}

Era Pemerintahan orde lama pada masa kepemimpinan Presiden Soekarno terdapat sejumlah proyek pembangunan yang dilakukan di lahan gambut, utamanya untuk tujuan peningkatan produksi pangan. Ekstensifikasi pertanian melalui pembukaan lahan baru untuk persawahan mencakup lahan gambut di Kalimantan dan Sumatera. Pembangunan kanal-kanal dalam skema proyek Dredge, Drain, and Reclamation di bawah komando Kementerian Pekerjaan Umum dan Tenaga dilakukan agar akses ke lahan rawa menjadi lebih mudah. Terdapat dua kanal yang relatif panjang di Kalimantan dan Sumatera, masing-masing adalah kanal Banjarmasin - Pontianak dengan panjang 760 km dan kanal Palembang - Tanjung Balai dengan panjang $850 \mathrm{~km}$ (Haryono 2012).

Narasi kebijakan budidaya gambut ini berlanjut di era Soeharto yang dijalankan melalui Proyek Pembukaan Persawahan Pasang Surut (P4S) tahun 1969 di bawah koordinasi Kementerian Pekerjaan Umum dan Tenaga (Haryono 2012). Proyek ini berhasil membuka sekitar 1,24 juta $\mathrm{Ha}$ meliputi pembangunan 29 jaringan tata air di Kalimantan 
Tabel 1. Diskursus Kebijakan Pengelolaan dan Budidaya Gambut Nasional

\begin{tabular}{|c|c|c|}
\hline Latar Situasi & Kebijakan & Istilah yang dipakai \\
\hline \multirow{5}{*}{$\begin{array}{l}\text { Tingginya kebutuhan pangan dan produk pertanian untuk } \\
\text { konsumsi domestik dan ekspor (Osaki et al. 2016). } \\
\text { Berkurangnya lahan pertanian akibat adanya alih fungsi } \\
\text { menjadi lahan pemukiman, pembangunan perkotaan, dan } \\
\text { sebagainya }\end{array}$} & Keppres 32/1990 & Kawasan Bergambut \\
\hline & Keppres 82/1995 & Lahan Gambut \\
\hline & Keppres 74/1998 & \\
\hline & Keppres 133/1998 & \\
\hline & Keppres 80/1999 & $\begin{array}{l}\text { Kawasan Bergambut dan } \\
\text { Lahan Gambut }\end{array}$ \\
\hline \multirow{9}{*}{$\begin{array}{l}\text { Semakin menguatnya isu perubahan iklim pasca Indonesia } \\
\text { menjadi tuan rumah Conference of Parties UNFCCC ke - } \\
13 \text { di Bali dan menghasilkan Bali Roadmap. Disusul hasil } \\
\text { COP ke }-15 \text { di Copenhagen dan COP ke - } 16 \text { di Cancun, } \\
\text { serta Pertemuan G8 tahun } 2009 \text { di Pittsburgh. Indonesia } \\
\text { berkomitmen untuk menurunkan emisi gas rumah kaca } \\
\text { sebesar } 26 \% \text { dengan usaha sendiri dan } 41 \% \text { dengan } \\
\text { bantuan Internasional. } \\
\text { Semakin terbukanya rezim terhadap investasi asing } \\
\text { mendorong Pemerintah lebih serius menangani keluhan- } \\
\text { keluhan lingkungan hidup karena tingginya dorongan dari } \\
\text { luar (dunia internasional). } \\
\text { Perubahan struktur politik, terbukanya Pemerintah dalam } \\
\text { merespon keluhan dan protes kolektif lingkungan hidup, } \\
\text { terutama dalam kerangka penghentian pencemaran dan } \\
\text { kerusakan lingkungan hidup. } \\
\text { Kebakaran hutan dan lahan pada } 2006 \text { dengan luasan } \\
\text { terbesar setelah tahun 1997/98. }\end{array}$} & Inpres $2 / 2007$ & Lahan Gambut \\
\hline & UU No. $26 / 2007$ & Kawasan Bergambut \\
\hline & 'PP 26/2008 & Kawasan Bergambut \\
\hline & UU 32/2009 & Ekosistem Lahan Gambut \\
\hline & PerMentan 14/2009 & Gambut \\
\hline & & Lahan Gambut \\
\hline & $\begin{array}{l}\text { PerMen Negara LH } \\
10 / 2010\end{array}$ & Lahan Gambut \\
\hline & Perpres No. 61/2011 & Lahan Gambut \\
\hline & $\begin{array}{l}\text { Inpres } 10 / 2011 \\
\text { (diperbaharui setiap } 2 \\
\text { tahun dan berjalan } \\
\text { sampai saat ini) }\end{array}$ & Lahan Gambut \\
\hline \multirow{4}{*}{$\begin{array}{l}\text { Semakin terbukanya struktur kesempatan politik. } \\
\text { Perubahan struktur politik pasca Pemilu, masuknya elite } \\
\text { gerakan sipil dalam struktur pemerintahan. } \\
\text { Kebakaran hutan dan lahan skala besar tahun } 2015\end{array}$} & PP No. 71/2014 & Gambut \\
\hline & $\begin{array}{l}\text { jo. } \\
\text { PP No. 57/2016 }\end{array}$ & Ekosistem Gambut \\
\hline & & Kesatuan Hidrologis \\
\hline & PP No. $1 / 2016$ & \\
\hline
\end{tabular}

Selatan dan 22 jaringan tata air di Sumatera dan Kalimantan Barat.

Dinamika aktor dalam struktur politik di akhir era Orde Baru mulai menggeser diskursus kebijakan terkait gambut ke arah perlindungan setelah dikeluarkannya Keputusan Presiden (Keppres) Nomor 32 Tahun 1990 tentang Pengelolaan Kawasan Lindung. Secara umum munculnya Keppres tersebut bertujuan untuk mencegah timbulnya kerusakan fungsi lingkungan hidup (Sitorus dan Maryam 2018). Meskipun demikian, narasi utama kebijakan era Orde Baru ini masih bertujuan pemanfaatan lahan gambut untuk budidaya diidentifikasi dengan adanya Keppres Nomor 82/1995 jo. Keppres 74/1998 tentang Pengembangan Lahan Gambut untuk Pertanian Tanaman Pangan di Kalimantan Tengah sebagai landasan berjalannya Proyek Pengembangan Lahan
Gambut (PLG) seluas satu juta hektar di Provinsi Kalimantan Tengah.

Pada era transisi reformasi melalui Keppres Nomor 80/1999 tentang Pedoman Umum Perencanaan dan Pengelolaan Kawasan Pengembangan Lahan Gambut di Kalimantan Tengah, terdapat dua diskursus kebijakan terkait gambut, yakni perlindungan dan pengelolaan. Hal ini tercermin dalam teks kebijakan yang memuat adanya pembagian fungsi kawasan bergambut menjadi dua, yakni: (1) fungsi kawasan lindung, dengan ketebalan gambut $\geqslant 3$ meter yang dimanfaatkan untuk konservasi di bawah kewenangan pengelolaan Departemen Kehutanan dan Perkebunan; dan (2) fungsi kawasan budidaya, dengan ketebalan gambut $<3$ meter untuk pemanfaatan budidaya pertanian, perikanan, perkebunan, dan kehutanan. Adanya pembagian fungsi tersebut menunjukkan 
bahwa Pemerintah mulai menaruh perhatian pada konservasi gambut yang sangat rentan terhadap kerusakan. Hal ini tidak terlepas dari adanya peristiwa kebakaran skala besar di berbagai belahan dunia antara tahun 1997 hingga 1998 yang menghanguskan lahan seluas 25 juta Ha, termasuk 11,7 juta Ha hutan di Indonesia (Rasyid 2014). Selain pembagian fungsi tersebut, Keppres Nomor 80/1999 ini juga melibatkan adanya studi Analisis Mengenai Dampak Lingkungan (AMDAL) secara terpadu di bawah koordinasi Badan Koordinasi Tata Ruang Nasional.

\section{Periode 2007 - 2014}

Selama kurun tahun 2007 - 2014 narasi kebijakan pengelolaan dan budidaya gambut semakin mengarah ke perlindungan dan rehabilitasi lahan gambut. Peristiwa kebakaran hutan dan lahan pasca reformasi yang terjadi pada tahun 2006 telah membuat dunia internasional menekan Indonesia untuk memberikan perhatian lebih besar pada perbaikan tata kelola gambut.

Perubahan struktur politik pasca reformasi telah membuka kesempatan bagi masuknya wacana gerakan lingkungan hidup ke dalam agenda kebijakan nasional. Terbukanya akses informasi menjadi faktor utama meningkatnya protes kolektif dan gerakan lingkungan hidup yang kemudian direspon pemerintah dengan membuat kebijakan yang mendukung perbaikan kualitas lingkungan hidup di Indonesia. Menurut Situmorang (2013), semakin terbukanya rezim terhadap investasi asing telah membuat semakin tingginya dorongan dari luar Indonesia agar Pemerintah Indonesia lebih serius menangani keluhankeluhan lingkungan hidup yang dirasakan oleh masyarakat dengan arus utama wacana adalah menghentikan pencemaran dan kerusakan lingkungan hidup, termasuk kebakaran hutan dan lahan gambut.
Beberapa kebijakan terkait pengelolaan gambut yang berorientasi pada perlindungan dan rehabilitasi lahan gambut dikeluarkan pada periode ini, antara lain Instruksi Presiden (Inpres) Nomor 2/2007, Peraturan Pemerintah (PP) 26/2008, dan Peraturan Presiden (Perpres) Nomor 61/2011 yang secara khusus memasukkan lahan gambut ke dalam aspek kegiatan Rencana Aksi Nasional Penurunan Emisi Gas Rumah Kaca (RAN-GRK) dengan target penurunan emisi karbon/gas rumah kaca dari bidang kehutanan dan lahan gambut sebesar 26\% atau 672 Megaton CO2e dengan usaha sendiri, atau $41 \%$ atau 1.039 Megaton $\mathrm{CO} 2 \mathrm{e}$ dengan dukungan internasional. Selain itu, terdapat dua produk kebijakan berupa UndangUndang (UU) yang memperkuat aspek perlindungan lahan gambut, yakni UU Nomor 26/2007 yang menempatkan gambut sebagai bagian dari kawasan lindung dan UU Nomor 32/2009 yang memuat tentang kriteria kerusakan gambut.

Meskipun secara garis besar kebijakan nasional pengelolaan gambut pada periode ini berorientasi untuk perlindungan dan rehabilitasi, namun masih ada beberapa kebijakan yang dikeluarkan dengan narasi mendukung budidaya di lahan gambut. Peraturan Menteri Pertanian (PerMentan) Nomor 14 Tahun 2009 tentang Pedoman Pemanfaatan Lahan Gambut untuk Budidaya Kelapa Sawit dikeluarkan sebagai dasar hukum bagi pelayanan pemberian izin usaha perkebunan yang memanfaatkan lahan gambut. Selain itu, masih terdapat penerbitan izin usaha pemanfaatan hasil hutan kayu oleh Kementerian Kehutanan di lahan gambut yang masuk dalam kawasan hutan.

\section{Periode 2014 - 2017}

Pada tahun 2014 Pemerintah Indonesia mengeluarkan kebijakan 'PP Gambut', yakni PP Nomor 71/2014 tentang Perlindungan dan 
Pengelolaan Ekosistem Gambut. Isi kebijakan ini mulai menunjukkan cara pandang ekologi terhadap gambut sebagai sebuah satu kesatuan ekosistem tersendiri, bukan sekedar lahan sebagai sumberdaya yang bernilai sosial dan ekonomi. Narasi utama kebijakan ini berorientasi untuk melindungi ekosistem gambut dan mempercepat upaya rehabilitasi dan
Pasca terjadinya kebakaran hutan dan lahan tahun 2015 yang mencakup areal gambut di Indonesia, serta untuk menyesuaikan struktur politik yang ada, maka Pemerintah memperkuat implementasi kebijakan gambut dengan mengeluarkan PP Nomor 1/2016 tentang Badan Restorasi Gambut dan PP Nomor 57/2016 tentang Perubahan Atas PP Nomor

Tabel 2. Dinamika Parameter ACF Pada Kebijakan Pengelolaan dan Budidaya Gambut

\begin{tabular}{|c|c|c|c|}
\hline \multicolumn{4}{|c|}{ Parameter Tetap } \\
\hline 1. & Permasalahan dasar & \multicolumn{2}{|c|}{$\begin{array}{l}\text { Kebakaran hutan dan lahan gambut karena karakteristik lahan gambut mudah teroksidasi } \\
\text { menjadi permasalahan utama pengelolaan dan budidaya gambut. }\end{array}$} \\
\hline 2. & $\begin{array}{l}\text { Distribusi dasar } \\
\text { sumberdaya }\end{array}$ & \multicolumn{2}{|c|}{$\begin{array}{l}\text { Perbedaan tujuan dalam pelaksanaan kebijakan, akibat adanya perbedaan diskursus dan } \\
\text { kepentingan para pihak. Terdapat } 2 \text { cara pandang utama, yang pertama melihat gambut } \\
\text { sebagai sebuah komoditas/sumberdaya yang dapat dimanfaatkan untuk meningkatkan } \\
\text { produktivitas pertanian dan industri perkebunan dan hutan tanaman, yang kedua melihat } \\
\text { gambut sebagai suatu kesatuan ekosistem rentan yang harus dilindungi. }\end{array}$} \\
\hline 3. & $\begin{array}{l}\text { Struktur dan nilai } \\
\text { dasar sosial }\end{array}$ & \multicolumn{2}{|c|}{$\begin{array}{l}\text { Kerusakan gambut akibat lemahnya tingkat kepatuhan terhadap prinsip-prinsip } \\
\text { pengelolaan yang lestari dengan memperhatikan karakteristik khas gambut. } \\
\text { Ketidakadilan pemanfaatan sumberdaya alam sehingga menghasilkan keyakinan anti } \\
\text { korporasi. }\end{array}$} \\
\hline 4. & $\begin{array}{l}\text { Peraturan yang } \\
\text { berlaku }\end{array}$ & \multicolumn{2}{|c|}{$\begin{array}{l}\text { Perubahan peraturan yang berlaku menunjukkan penguatan peran LSM dan akademisi } \\
\text { dalam perbaikan tata kelola gambut. }\end{array}$} \\
\hline \multicolumn{4}{|c|}{ Parameter Eksternal } \\
\hline No. & Parameter & Sebelum 2007 & $2007-20014$ \\
\hline 1. & $\begin{array}{l}\text { Perubahan kondisi } \\
\text { sosial ekonomi }\end{array}$ & $\begin{array}{l}\text { Tingginya kebutuhan pangan } \\
\text { dan produksi pertanian untuk } \\
\text { konsumsi domestik dan } \\
\text { ekspor }\end{array}$ & $\begin{array}{l}\text { Keluhan masyarakat terhadap perbaikan kualitas kesehatan } \\
\text { dan kesejahteraan yang terganggu akibat kebakaran dan } \\
\text { kerusakan lingkungan. } \\
\text { Semakin terbukanya pemerintah terhadap dukungan dan } \\
\text { investasi asing yang menyaratkan perbaikan kualitas } \\
\text { lingkungan hidup. }\end{array}$ \\
\hline 2. & $\begin{array}{l}\text { Perubahan pada opini } \\
\text { publik }\end{array}$ & $\begin{array}{l}\text { Tuntutan masyarakat pada } \\
\text { ketahanan pangan nasional }\end{array}$ & $\begin{array}{l}\text { Menguatnya dorongan publik terhadap perbaikan kualitas } \\
\text { lingkungan dan isu perubahan iklim. Isu kebakaran hutan } \\
\text { dan lahan skala besar di tahun } 2006 \text { dan } 2015 \text {. }\end{array}$ \\
\hline \multirow{2}{*}{3.} & \multirow{2}{*}{$\begin{array}{l}\text { Perubahan pada } \\
\text { sistem koalisi } \\
\text { pemerintahan }\end{array}$} & \multirow{2}{*}{$\begin{array}{l}\text { Struktur kesempatan politik } \\
\text { yang cenderung tertutup bagi } \\
\text { gerakan lingkungan hidup } \\
\text { dalam agenda pemerintah. }\end{array}$} & $\begin{array}{l}\text { Semakin terbukanya struktur kesempatan politik membuat } \\
\text { isu konservasi dan perbaikan lingkungan hidup masuk } \\
\text { dalam agenda pemerintah. }\end{array}$ \\
\hline & & & $\begin{array}{ll}\text { Elite gerakan lingkungan masuk } \\
\text { dalam koalisi pemerintahan } \\
\text { pemenang pemilu }\end{array}$ \\
\hline \multirow[b]{2}{*}{4.} & \multirow[b]{2}{*}{$\begin{array}{l}\text { Kebijakan politik dan } \\
\text { pengaruh dari } \\
\text { subsistem lain }\end{array}$} & \multirow[b]{2}{*}{$\begin{array}{l}\text { Kebijakan terkait } \\
\text { transmigrasi dan } \\
\text { pembangunan pertanian } \\
\text { (revolusi hijau) }\end{array}$} & $\begin{array}{l}\text { Tekanan dari dunia internasional untuk penyelasaian } \\
\text { permasalahan lingkungan terutama yang terkait isu } \\
\text { perubahan iklim, kebakaran hutan dan lahan. } \\
\text { Bali Road-Map hasil Conference of Parties ke-13 di Bali }\end{array}$ \\
\hline & & & $\begin{array}{ll}\text { Perhatian pemerintah dalam } \\
\text { menyelesaikan masalah } \\
\text { kebijakan pengelolaan gambut } \\
\text { ditandai dengan dibuatnya unit } \\
\text { kerja khusus dalam pengelolaan } \\
\text { gambut langsung di bawah } \\
\text { Presiden. } \\
\end{array}$ \\
\hline
\end{tabular}

restorasi ekosistem gambut di Indonesia yang selama periode sebelumnya mengalami banyak kerusakan.
71/2014 tentang Perlindungan dan Pengelolaan Ekosistem Gambut. Badan Restorasi gambut 
merupakan sebuah unit kerja khusus yang berkewenangan sebagai pelaksana koordinasi dan teknis di bawah naungan Presiden.

\section{Koalisi dalam Proses Kebijakan Pengelolaan} dan Budidaya Gambut

Pendekatan ACF menggunakan parameter tetap dan parameter eksternal dalam kaitannya melihat arah koalisi dan cara pandang aktor. Parameter tetap meliputi permasalahan dasar, distribusi dasar sumberdaya, struktur dan nilai dasar sosial, dan peraturan yang berlaku. Sementara parameter eksternal yang mempengaruhi cara pandang aktor terdiri atas: perubahan sosial ekonomi, perubahan opini publik, perubahan sistem koalisi pemerintahan, kebijakan politik dan pengaruh dari subsistem lain. Parameter eksternal tersebut diidentifikasi melalui telaah diskursus pada teks kebijakan. Parameter ACF pada telaah kebijakan pengelolaan dan budidaya gambut diuraikan dalam Tabel 2.

Berdasarkan analisa parameter tetap dan parameter eksternal pendekatan ACF maka ditemukan arah kebijakan gambut adalah:

1. Sebelum 2007, Kebijakan berorientasi pada pemanfaatan lahan gambut untuk budidaya pertanian, perkebunan, dan pembangunan hutan tanaman.

2. 2007 - 2014, Kebijakan bertujuan untuk merehabilitasi dan melindungi lahan gambut dalam upaya mitigasi perubahan iklim dan mencegah kebakaran hutan dan lahan. Meskipun demikian, karena gambut masih dilihat sebagai sub-ordinate dari sistem kebijakan sehingga izin-izin pemanfaatan hutan masih diberikan selama status kawasan masuk dalam fungsi produksi.
3. 2014 - 2017, Kebijakan berorientasi pada perlindungan, pengendalian kerusakan, dan pemulihan gambut sebagai satu kesatuan ekosistem.

\section{Analisa Aktor Pembentuk Koalisi}

Berdasarkan kecenderunan pemikiran para pihak (Tabel 3) yang diperoleh dari hasil interpretasi wacana di media massa dan analisa pada peraturan yang dikeluarkan oleh Pemerintah, serta diverifikasi melalui wawancara maka terdapat dua koalisi para aktor. Masing-masing koalisi mengusung logika sistem kepercayaan (belief system) yang saling berbeda dalam kerangka pendekatan Advocacy Coalition Framework (ACF). Kedua arah logika sistem kepercayaan sekaligus koalisi yang terbentuk tersebut yaitu:

1. Koalisi A: mengusung logika sistem kepercayaan (belief system) bahwa gambut sebagai salah satu sumberdaya lahan yang tersisa dan potensial dikembangkan untuk kegiatan budidaya, baik pertanian, perkebunan, maupun kehutanan;

2. Koalisi B: mengusung logika sistem kepercayaan (belief system) bahwa gambut sebagai satu kesatuan ekosistem yang harus dilindungi dan direhabilitasi apabila kondisinya telah rusak.

\section{Kontestasi Diskursus}

Berdasarkan kecenderungan pemikiran para aktor yang terlibat dalam proses kebijakan pengelolaan gambut di Indonesia, maka dapat diidentifikasi kontestasi diskursus melalui posisi para pihak dalam dinamika perubahan kebijakan berdasarkan periodesasi yang sebelumnya dibuat sebagaimana disajikan dalam Tabel 4. 
Tabel 3. Kecenderungan Pemikiran Penentu Posisi Koalisi Aktor

\begin{tabular}{|c|c|}
\hline Aktor & Kecenderungan Pemikiran \\
\hline Pemerintah Pusat & $\begin{array}{l}\text { Merupakan pembuat keputusan tertinggi di tingkat nasional dengan } \\
\text { Presiden sebagai pemegang kewenangan tertinggi. Perubahan } \\
\text { kecenderungan pemikiran aktor pada tiap periode ditentukan oleh } \\
\text { perubahan konstalasi politik yang terjadi. }\end{array}$ \\
\hline $\begin{array}{l}\text { Kementerian Lingkungan } \\
\text { Hidup dan Kehutanan (KLHK) }\end{array}$ & $\begin{array}{l}\text { Aktor memiliki kewenangan utama dalam implementasi PP Gambut. } \\
\text { Memiliki kecenderungan pemikiran bahwa gambut merupakan } \\
\text { ekosistem yang harus dilindungi dan direhabilitasi sehingga mampu } \\
\text { mencegah terjadinya kebakaran dan kerusakan lingkungan hidup. } \\
\text { Sebelum tahun 2014, Aktor terbagi menjadi dua: (1) Kementerian } \\
\text { Kehutanan; dan (2) Kementerian Lingkungan Hidup. }\end{array}$ \\
\hline Kementerian Kehutanan & $\begin{array}{l}\text { Memiliki kewenangan membuat peraturan di tingkat nasional berupa } \\
\text { PerMen/KepMen yang mengikat semua pihak yang berkepentingan } \\
\text { terhadap kawasan hutan. Memiliki kecenderungan pemikiran } \\
\text { memaksimalkan pemanfaatan lahan gambut untuk budidaya. }\end{array}$ \\
\hline $\begin{array}{l}\text { Kementerian Lingkungan } \\
\text { Hidup }\end{array}$ & $\begin{array}{l}\text { Memiliki kecenderungan pemikiran melindungi gambut dengan } \\
\text { mencegah kerusakan dan penurunan kualitas ekosistem gambut. }\end{array}$ \\
\hline Kementerian Pertanian & $\begin{array}{l}\text { Lahan gambut dapat dimanfaatkan sebagai lahan budidaya untuk } \\
\text { pertanian dan perkebunan sepanjang sesuai dengan karakteristik } \\
\text { lahannya. }\end{array}$ \\
\hline Badan Restorasi Gambut (BRG) & $\begin{array}{l}\text { Adanya kebijakan PP gambut bertujuan untuk mengembalikan fungsi } \\
\text { lahan gambut dan menekan potensi terjadinya kembali kebakaran } \\
\text { hutan dan lahan. }\end{array}$ \\
\hline $\begin{array}{l}\text { Asosiasi Pengusaha Hutan } \\
\text { Indonesia (APHI) }\end{array}$ & $\begin{array}{l}\text { Aktor merupakan kelompok pengusaha di bidang kehutanan. Aktor } \\
\text { memandang implementasi atas kebijakan PP gambut akan mematikan } \\
\text { hutan tanaman industri terutama penghasil bahan baku kertas. }\end{array}$ \\
\hline $\begin{array}{l}\text { Gabungan Pengusaha Kelapa } \\
\text { Sawit Indonesia (GAPKI) }\end{array}$ & $\begin{array}{l}\text { Perubahan kebijakan menimbulkan ketidakpastian iklim investasi. } \\
\text { Adanya tumpang tindih areal konsesi dengan kawasan restorasi } \\
\text { gambut menjadikan biaya produksi makin tinggi karena harus } \\
\text { membuat kembali rencana produksi dan mencari lahan pengganti } \\
\text { (land swap) yang belum dipastikan clean and clear persoalan } \\
\text { tenurialnya. }\end{array}$ \\
\hline $\begin{array}{l}\text { Lembaga Penyelidikan } \\
\text { Ekonomi dan Masyarakat } \\
\text { Universitas Indonesia (LPEM } \\
\text { UI) }\end{array}$ & $\begin{array}{l}\text { Implementasi PP Gambut akan menghambat investasi pada sektor } \\
\text { perkebunan dan kehutanan, yang kemudian akan berimplikasi pada } \\
\text { naiknya tingkat pengangguran, menurunnya pendapatan daerah dan } \\
\text { tingkat kesejahteraan masyarakat, serta terbengkalainya } \\
\text { pembangunan infrastruktur. }\end{array}$ \\
\hline $\begin{array}{l}\text { Himpunan Gambut Indonesia } \\
\text { (HGI) }\end{array}$ & $\begin{array}{l}\text { Gambut merupakan lahan yang potensial untuk dimanfaatkan sebagai } \\
\text { lahan budidaya ketika ketersediaan lahan mineral semakin berkurang } \\
\text { karena adanya konversi untuk pemukiman, pembangunan } \\
\text { infrastruktur, dan sebagainya. Implementasi PP Gambut akan } \\
\text { berdampak pada timbulnya masalah investasi, berkurangnya } \\
\text { pendapatan daerah, dan terjadinya persoalan sosial di masyarakat. }\end{array}$ \\
\hline $\begin{array}{l}\text { Gerakan Masyarakat Sipil } \\
\text { Lingkungan Hidup: } \\
\text { 1. Wahana Lingkungan Hidup } \\
\text { (WALHI) } \\
\text { 2. Jaringan Advokasi Tambang } \\
\text { (JATAM) }\end{array}$ & $\begin{array}{l}\text { Mendukung kebijakan terkait perlindungan ekosistem gambut. } \\
\text { Menolak budidaya di ekosistem rawa gambut karena akan merusak } \\
\text { kualitas lingkungan hidup yang ada. }\end{array}$ \\
\hline
\end{tabular}

Tabel 4. Dinamika Para Pihak dalam Koalisi

\begin{tabular}{llll}
\hline Aktor & Sebelum 2007 & $\mathbf{2 0 0 7 - \mathbf { 2 0 1 4 }}$ & $\mathbf{2 0 1 4 - \mathbf { 2 0 1 7 }}$ \\
\hline Koalisi A & 1. Pemerintah Pusat & 1. Kementerian Pertanian & 1. Kementan \\
& 2. APHI & 2. APHI & 2. APHI \\
& 3. GAPKI & 3. GAPKI & 3. GAPKI \\
& & 4. Kementerian & 4. LPEM UI \\
& & Kehutanan & 5. HGI \\
\hline Koalisi B & 1. Gerakan Masyarakat & 1. Pemerintah Pusat 2. & 1. Pemerintah Pusat \\
& Sipil Lingkungan Hidup & Kementerian Lingkungan & 2. Kementerian Lingkungan \\
& (WALHI, JATAM) & Hidup & Hidup dan Kehutanan \\
& & 3. Gerakan Masyarakat & 3. BRG \\
& & Sipil Lingkungan Hidup & 4. Gerakan Masyarakat \\
& & (WALHI, JATAM) & Sipil Lingkungan Hidup \\
& & & (WALHI, JATAM) \\
\hline
\end{tabular}




\section{Kesimpulan}

Dinamika kebijakan pengelolaan dan budidaya ekosistem gambut di Indonesia dipengaruhi oleh adanya perubahan struktur dan konstalasi politik kekuasaan dengan melibatkan diskursus masingmasing aktor yang diusung dalam koalisi. Kebijakan yang ada saat ini ditujukan untuk melindungi dan merehabilitasi ekosistem gambut yang ada dengan tetap membuka kesempatan bagi pemanfaatan lahan gambut untuk budidaya sepanjang menyesuaikan karakteristik ekosistem gambut dan mampu mencegah potensi terjadinya kebakaran.

Melalui pendekatan Advocacy Coalition Framework yang digunakan diperoleh dua koalisi yang masing-masing mengusung arah logika sistem kepercayaan (belief system), yakni: (1) Koalisi A yang meyakini lahan gambut sebagai sumberdaya yang potensial dikembangkan untuk budidaya pertanian, perikanan, perkebunan, dan hutan tanaman; dan (2) Koalisi B yang memandang ekosistem gambut sebagai ekosistem rentan yang harus dilindungi dan direhabilitasi. Oleh karena itu, agar tujuan pengelolaan ekosistem gambut yang lestari dapat dicapai maka dalam perumusan kebijakan Pemerintah perlu meletakkan konteks kepentingan para aktor dan kontestasi diskursus yang ada, sehingga diperoleh dukungan dari setiap koalisi terhadap kebijakan yang dibuat.

\section{Daftar Pustaka}

Ardhian D, Adiwibowo S, Wahyuni ES. 2016. Peran dan Strategi Organisasi Non Pemerintah dalam Arena Politik Lingkungan Hidup. Jurnal Sosiologi Pedesaan 4 (3): $210-216$.

Arshanti L, Kartodihardjo H, Khan A. 2017. Masalah dan Kebijakan Sertifikasi Pengelolaan Hutan Alam Produksi Lestari: Penerapan Advocacy Coalition Framework. Jurnal Analisis Kebijakan Kehutanan 14 (2): 137 - 148.
Arts B. 2012. Forest Policy Analysis and Theory Use: Overview and Trends. Journal Forest Policy and Economics. 16:7-13.

Haryono. 2012. Lahan Rawa: Lumbung Pangan Masa Depan Indonesia. Jakarta: IAARD Press-Badan Penelitian dan Pengembangan Pertanian.

Henry AD, et al. 2014. Policy Change in Comparative Contexts: Applying the Advocacy Coalition Framework Outside of Western Europe and North America. Journal of Comparative Policy Analysis: Research and Practice 16 (4): 299 - 312.

Masganti, Anwar K, Susanti MA. 2017. Potensi dan Pemanfaatan Lahan Gambut Dangkal untuk Pertanian. Jurnal Sumberdaya Lahan 11 (1): $43-52$.

Rasyid F. 2014. Permasalahan dan Dampak Kebakaran Hutan. Jurnal Lingkar Widyaiswara $1(4): 47-59$.

Sabiham S, Sukarman. 2012. Pengelolaan Lahan Gambut untuk Pengembangan Kelapa Sawit di Indonesia. Jurnal Sumberdaya Lahan 6 (2): 55 $-66$.

Situmorang AW. 2013. Dinamika Protes Kolektif Lingkungan Hidup di Indonesia (1968-2011). Yogyakarta (ID): Pustaka Pelajar.

Sitorus TB, Maryam R. 2018. Politik Hukum Pengelolaan Lahan Gambut di Indonesia. Jurnal Legislasi Indonesia 15 (3): 197 - 209.

Sotirov M, Memmler M. 2012. The Advocacy Coalition Framework in Natural Resource Policy Studies: Recent Experiences and Further Prospects. Journal Forest Policy and Economics 16: 51-64. 